\title{
Article \\ An Empirical Study of Drivers, Barriers, and Cost Efficiency of Information Systems in Greek Industry
}

\author{
Paraskevi Kapetanopoulou ${ }^{1, *}$ and Antigoni Kouroutzi ${ }^{2}$ \\ 1 Department of Mechanical Engineering, Aristotle University of Thessaloniki, 54124 Thessaloniki, Greece \\ 2 Faculty of Economics and Management, Open University of Cyprus, Latsia 2220, Cyprus; \\ antikourout@gmail.com \\ * Correspondence: vkapetan@auth.gr
}

check for updates

Citation: Kapetanopoulou, P.;

Kouroutzi, A. An Empirical Study of Drivers, Barriers, and Cost Efficiency of Information Systems in Greek Industry. Appl. Sci. 2021, 11, 3475. https://doi.org/10.3390/app11083475

Academic Editor:

Ricardo Colomo-Palacios

Received: 19 February 2021

Accepted: 12 April 2021

Published: 13 April 2021

Publisher's Note: MDPI stays neutral with regard to jurisdictional claims in published maps and institutional affiliations.

Copyright: (C) 2021 by the authors Licensee MDPI, Basel, Switzerland. This article is an open access article distributed under the terms and conditions of the Creative Commons Attribution (CC BY) license (https:// creativecommons.org/licenses/by/ $4.0 /)$

\begin{abstract}
The business environment is characterized by high complexity and competitiveness. This is the reason why information is considered to be the most valuable source companies have available. From the social point of view, information technology (IT) has a positive effect on business performance, creates strong and transparent relations with enterprise's clients, and increases competition. The purpose of this study is to assess the current state of information systems (ISs) adoption by Greek industry. The main issues that are explored through this survey in regards to IS adoption is the extent, the most important specific drivers and barriers, and the profitability due to IS adoption. The study also investigates whether motivators or inhibitors are affected by the factor of profitability due to IS adoption. The survey that was conducted is questionnaire-based and the responses were analyzed statistically using several statistical tools. The results suggest that the majority of the industries in Greece have adopted IS to conduct their business. Reducing errors that occur during their business activities seems to be their main motivation for IS adoption. On the other hand, they are hesitant to invest in an IS because of its cost.
\end{abstract}

Keywords: information systems; information technology; manufacturing industry; drivers; barriers; cost efficiency; profitability; Greece

\section{Introduction}

The business environment is characterized by high complexity and competitiveness. This is the reason why information-derived either from the internal or the external business environment-is considered to be the most valuable source the companies have available. Good information management can be proved to be crucial to their existence and prosperity as it helps the administration to adapt to strategies, avoid threats, utilize opportunities, change decisions, and effectively manage all the core and supportive company operations [1-3]. Globalization has increased the abundance of information being shared within the organizations along with the existing complexity and competitiveness rapidly. Thus, enterprises seek systems that would help them manage effectively the complexity of their operations along with the information they have available [1,4]. This renders necessary and worthwhile the investigation of the implementation of an information system (IS) or technology (IT) as IT systems enable and facilitate a wide range of business activities (storage, processing, distribution, transmission, reproduction of information etc.) [1,5-7].

Several researchers have paid considerable attention to IT being used for supply chain management (SCM) as they noticed that it has become popular among companies. That is the reason why in the more developed economies the competition has shifted among different supply chains (chain-chain) compared to the enterprise-enterprise competition that seems to still exist in less developed economies [8-11]. Generally, SCM can be considered as a way of approach that intends to put together under a single idea several parties such as manufacturers, suppliers, stores and warehouses. Companies have to be able to manufacture their products within the right time, distribute them in appropriate quantities 
to the right locations, so they can satisfy the service level requirements and at the same time to minimize the system wide costs. Adopting an IT seems necessary to be able to support their supply chains effectively and efficiently $[3,11]$. IT can be considered a critical factor in supply chain (SC) as they contribute not only to the performance of an independent enterprise but also to the SC as a whole. One of the critical elements companies can develop through the effective use of IT in the SCM is competitive advantage [2,11-14]. There are several types of IS that can be used to support logistics management such as: enterprise resource planning-ERP, warehouse management systems-WMS, transportation management systems-TMS, and other related technologies (barcode, electronic data interchange, etc.) $[7,14]$.

Several literature reviews have noted the need for empirical research and in particular for survey-based studies that could provide answers regarding the use of IT in several aspects of industry. Ketikidis et al. [10] call for more research regarding the use of IS for logistics and SCM so as to increase the number of companies that participated in their survey, which was conducted in South East Europe-including Greece. Other studies call for further research regarding the enablers and inhibitors of advanced IT adoption or other perspectives that affect the rate of IT adoption in small-medium enterprises (SMEs) [11,15]. Some researchers focus on a specific type of IS in an effort to discover its benefits. For example, Rouhani and Mehri [5] call for more research in ERP empowering benefits on industrial firms so as to extend their research to more companies, which would also allow comparisons. Besides that, some researchers call for inter-country comparisons [10] or comparisons between different sectors for cross learning [15]. Of course, several other publications exist regarding Information and Communication Technologies (ICTs), ISs or specific systems such as ERP-and the relationship between ERP and SCM performance [16], WMS, etc. Thus far, there are very few published survey-based studies regarding IS, IT, ICT, and SCM that have been conducted partially - as a part of a wider research that has been conducted in other countries too [10]—or entirely in Greece [1,6].

\section{Research Objectives}

Information technology (IT) offers opportunities for the enterprises to improve productivity, profitability and the performance of supply chain. According to Haseeb et al. [17] IT implementation has a positive effect on business performance, transforms business organization, increases competition and fosters innovation. Wereda and Wozniak [18] claim that ICTs implemented by the enterprise can create strong and transparent relations with its clients. Their study reveals that the relations with clients have the greatest share in shaping the development of innovative enterprises in the areas of minimizing the number of complaints, financial liquidity, and efficiency of core business processes.

The motivation behind the research presented in this paper was the need to assess the current use of IS in manufacturing companies in Northern Greece as well as the drivers and inhibitors they face regarding IS adoption. During the last decade Greece has been hit by a financial crisis that, of course, affected more than enough the Greek companies but also the multinational ones. Beyond the financial crisis the fact that Greece is close to countries with even lower economies and lower taxes has driven several companies to transfer their facilities and their administration in such countries to benefit more by their operations. Due to the landscape of Greece most of the companies that were affected were those located in Northern Greece because of their close proximity with the neighboring countries like Bulgaria, Turkey, and North Macedonia. Businesses, consumers, and suppliers quite often have financial transactions with these countries which affect negatively business affairs of SMEs. The same products or services can be found at lower prices by ordering them and delivered by companies located in the relevant countries or just by crossing the north borders of Greece. Under the peculiar conditions it was interesting to focus on the SMEs that can be easily affected by the bordering countries in contrast with companies located in South Greece.

Therefore, it is natural to pose the following broad question: 
- How much are manufacturing companies in Northern Greece using/adopting IS in an effort to manage the whole or part of their supply chain and what drives them to adopt those technologies or what prevents them?

The main objective of this research is to obtain specific, albeit tentative, answers to the above general question and gain a better understanding of the relevant issues in Northern Greek industry, including manufacturers and multinationals from outside Greece that are active (producing) in Greece, through a questionnaire-based survey about IS in the manufacturing sector. A parallel objective is to contribute to the knowledge about the relative importance of various drivers and barriers to the adoption of IS in European industry.

This empirical research contributes to filling the research gaps we described previously, by making the following contributions:

- It empirically investigates whether Greek companies use IS and if so, which kind of IS they use to conduct their business.

- It determines whether IS adoption is considered profitable for the companies.

- It also determines the importance of the drivers that motivate the enterprises to adopt IS as well as the importance of the barriers that prevent the adoption.

- It investigates whether there are factors that affect the drivers and barriers of IS adoption. The companies have been divided into two groups: The ones that use IS and those that do not. The two groups are being compared regarding the barriers of IS adoption. Another comparison is being set using as a factor the level of profitability they managed to accomplish due to IS adoption to determine whether there is a difference, regarding both the drivers and barriers of IS adoption.

The next section presents a literature review of the use of IS that is of interest to our research and develops specific research questions that are based on the available literature. Section 4 describes the research methodology and the data collection process. Section 5 contains the research results and the final section summarizes the main conclusions of this research, along with our propositions for future research.

\section{Literature Review and Research Questions}

The following literature review is limited to papers that are directly related to the general objective of this research. The review helps us to formulate specific research questions by grounding them in the literature and it is divided into sub-sections corresponding to the various sub-themes of the research, each concluding with the statement of the respective research question(s).

\subsection{Usage of Information Systems and Supply Chain Management}

Empirical studies that were conducted already in the 1990s or a little later consider that information systems (IS)/information technology (IT) help significantly in the development of new organizational forms, such as strategic partnership or networks [19]. Since then, IS/IT or information and communication technology (ICT) has emerged and managed to grow its influence among the enterprises. Companies have realized that through IS they have the opportunity to implement important innovations in their processes and also improve the efficiency of those processes that are utilized to produce their products/services [20]. Several researchers through many years have examined and analyzed the innovations that are derived from ICT/IT investments, the enablers or inhibitors of their adoption or even the possible impacts on the enterprises [21]. Recently managers and researchers seem to show a great interest in the application of IS in SCM because of the general realization that IS can improve not only the performance and efficiency of an individual firm but also the supply chain (SC) performance as a whole [22].

There are several ISs that can be used worldwide in industry in an effort to help the company's internal processes and also in regards with their supply chain management (SCM) with suppliers and customers. A brief presentation of the ISs that are used in the current research is given below: 
- $\quad \mathrm{SCM}$ (supply chain management)

- ERP (enterprise resource planning)

- WMS (warehouse management system)

- $\quad$ APS (advanced planning and scheduling)

- OMS (ordering management system)

- $\quad$ MES (manufacturing execution system)

- $\quad$ MRP (materials requirement planning)

- DRP (distribution requirements planning)

- TMS (transportation management system)

- $\quad$ CRM (customer relationship management)

- SRM (supplier relationship management)

It seems natural to start the description of the current state of use of IS from the industrial companies - domestic or foreign — of Northern Greece by exploring the level of penetration of IS in these companies and the kind of IS they use to conduct their business. Thus, the first research question is formulated as follows:

RQ1: How much do (or how many) manufacturers in Northern Greece use IS to deal with their affairs? Which kind of IS they have adopted and used to process their activities?

\subsection{Profitability of IS Adoption}

The business environment is characterized by major complexity in all of its functions and elements. Therefore, the information that is obtained from internal or external business environments needs to be processed and managed in a very systematic way to minimize uncertainty and to maximize profit at the same time. Profitability is the characteristic that can define the existence and longevity of a company in a very competitive environment. The advances in technology have made it possible to manage complexity and information more easily than ever before. Thus, many companies started to be interested in IS to manage the vast amount of information they have available during their operations $[1,16,23]$.

The first studies conducted about the business performance of companies that had adopted IS showed no promising results regarding the profitability of ICT adaptation. Promising results firstly appeared in the mid-1990s, although there were also contradicting findings, which suggest that there are probably other variables influencing the effect of ICT on business performance (e.g., the sector they operate in) [24-26].

Ketikidis et al. [10], in their study of Southeastern Europe's companies-including Greece-with regard to profitability, found that companies in that area are more focused on dealing with suppliers and less with customers. In other words, they try to gain profit from the customers, but the amount of profit they gain from their businesses is not determined. There are also studies that are focused on specific IS systems [27], examining the post implementation practices of ERP systems and their relationship to financial performance.

The focus of the second research question is set on the profitability of IS adaptation and it is expressed as follows:

RQ2: Is IS adoption considered as profitable in direct economic terms by Greek manufacturing companies?

\subsection{Drivers of IS Adoption}

There are various motivating factors for IS adoption by industry that several researchers have recognized and classified in different ways, which are by necessity subjective.

Competitive advantage is considered as one of the key factor which motivates companies to implement the latest IT to support their supply chain (SC) and stay on the cutting edge [28,29]. According to Appulu and Latham cost and time reductions are considered as two other key elements that force Nigerian SMEs (small-medium enterprises) into ICT adoption [29]. IT development has provided managers with several systems in their constant efforts to control their business performance more effectively and at the same time to achieve cost reduction $[23,30]$. As the competition among SCs seems more important than the competition among companies, the pressure the managers feel 
to meet customer demand, achieve customer satisfaction and loyalty is higher. Several ISs-especially CRM-emphasize on the importance of customer satisfaction and consider it as one of the non-financial benefits of new technologies [16,27,30]. Errors/mistakes can occur in every stage of the SC and cause great trouble. The fewer errors that exist, and the sooner they are discovered, the better for the enterprises. Late discovery might lead to financial loss for the company. For example, some products may need to be discarded. One of the major problems especially in SMEs is considered to be the human factor, not only because humans are susceptible to mistakes by nature, but also because they might not be trained into the specific IS used by the company [31]. Production planning is making manufacturing more efficient, providing flexibility because it can adapt to customers' demand [12] and it can lead to lower inventory levels of all types of materials and products, which eventually leads to inventory cost reduction [13]. In the research by Koh et al. [31] that was conducted in Greece, one of the respondents mentioned that one of the benefits of the ERP system they were using was that it helped them to minimize their inventory because of the improvements in production planning and control. When a company aims at good inventory management it mostly means that it seeks low inventory levels and high availability of required materials. In their research regarding the positive impact of demand forecasting and inventory management, Li et al. [9] concluded that both these processes help the company to reduce overproduction, leading to lower costs and stock levels. WMS is the IS that is usually used for inventory control $[7,10]$. Companies rely on their suppliers to operate smoothly and meet their customers' demands and-as a chain-suppliers must be able to meet their customers'-companies' demands too. For example, low lead time, which is the time that is needed since the customer places an order until the product is delivered, can affect the customers' production planning and scheduling. Thus, it is crucial for a company to select the appropriate supplier and avoid problems which might occur in their operations. Managers are able to assess a supplier's performance by checking several variables such as: lead time, order fill capacity, logistics cost, delivery reliability, advanced shipment notification, etc. [12].

The focus of the current research is placed on seven reasons that would motivate upper management of manufacturing companies to invest in IS. Thus, the third research question is formed as follows:

RQ3: Competitive advantage, customers' satisfaction, cost reduction of all forms, error reduction in several business operations, production planning, inventory management, and appropriate supplier selection have been recognized, among others, as important factors motivating IS adoption in industry. Which of those are the main drivers for (North) Greek manufacturing companies?

It is noted that the drivers that are explicitly included in RQ3 are not the only ones that, according to literature, can motivate companies into adopting IS.

\subsection{Barriers to IS Adoption}

Although there are more than enough good reasons for the manufacturing industry to adopt IS, at the same time there are enough obstacles which prevent them from implementing one. Since only six barriers are chosen to be explored in detail, the authors of this paper acknowledge the subjectivity of their choice and the framing of these six particular barriers. Due to the fact that the research was conducted in Greece, it was deemed appropriate to include the current financial crisis in the country (since 2009) as a possible barrier.

High cost of technology is considered as a major inhibitor for ICT widespread adoption and use as it poses additional cost to the companies which is why-especially SMEs-avoid implementation [6,32]. Cost forces smaller enterprises to implement a mid-range ERP compared to the large-scale ERP that is more probably implemented by medium or large companies. That is the reason why ERP's predecessors (MRP, MRPII etc.) are still very popular among SMEs [10]. Human factor sometimes plays a significant part in a company's decision to adopt IT or not, especially in SMEs. Employees can occasionally be reluctant to change and resist on new IT implementation. Lack of training on the specific system 
that is about to be installed or generally in new technologies can be a significant reason for employees' opposition to IT adoption. Thus, the management should communicate and justify the reasons the company needs the new IT and find motives for their employees to go along. On the other hand, it is possible for the administration to prioritize the investment in another field in comparison to the implementation of a new IT because that field seems more problematic or more interesting to them (e.g., educate employees in new technologies) $[5,33]$. Over the last decade (since 2009) Greece's economy was severely hit by a financial crisis that led to a period of prolonged recession with very visible results in industry too. That peculiarity in Greek region poses an additional research interest that leads scholars and policy-makers to emphasize on the fact that ICT/IS can perform a crucial role on the attempts the country makes to recover from that financial crisis and start to develop again taking also into consideration that the company was not severely hit by that crisis [6]. The size of an enterprise plays a significant part regarding IT adoption and can become an important discriminator between those which adopt or not-adopt a form of IT. When the need to communicate and store information is low, companies feel the need for advanced IT adoption less compelling [15]. Thus, it is more probable for them to prefer to operate with their current system-regardless if it is an IS or not. The current financial crisis also contributes to that effect.

Taking all the above into account the fourth research question can be posed as following:

RQ4: Cost of IS, financial crisis, systems that satisfy completely or at a sufficient level, other priorities and employees' resistance have been recognized, among others, as possible obstacles to adopt IS. Which of those are the main barriers to a broader adoption of IS in (Northern Greek) industry?

Before we proceed it is pertinent to assess that there was an "open type" option included in the questionnaire. In this case the respondents were given the opportunity to mention any other motive/barrier they consider equally important. None of the respondents opted to take into consideration this "open choice" and write down any additional motive/barrier.

\subsection{Factors Affecting Drivers and Barriers of IS Adoption}

In addition to investigating the profitability, the adoption, drivers, and barriers of IS adoption in the Northern Greek industry as a whole, it is interesting to explore whether and how much these issues are affected by two factors that are arguably important, namely (a) IS adoption, and (b) IS profitability. A specific definition of these factors is provided bellow:

(a) IS adoption. The notation ISO is used for companies that are not currently using IS for their operations and the notation IS1 for those companies that have adopted IS in order to better manage their operations. A comparison of the responses of these two groups is limited to the barriers of IS adoption and the following research question is posed: RQ5: Are there significant differences between IS0 companies and IS1 companies regarding the perceived barriers to IS adoption?

(b) IS Profitability. Focusing on IS1 companies and profitability, two different groups of companies can be defined: those with high level of profitability due to IS adoption (IS_H) and those with medium profitability level due to IS adoption (IS_RS). These two groups are being compared against both drivers and barriers of IS adoption. Then the research question can be posed as follows: RQ6: Is there any significant difference between IS_H companies and IS_RS companies regarding the perceived drivers and barriers of IS adoption?

\section{Research Methodology and Data Collection}

The population for this study was based on manufacturing companies that are active in Northern Greece in the peripheral districts of Macedonia and Thrace. The questionnaire was sent via e-mail to several companies the list of which was obtained from ICAP's Greek Financial Directory [34], volume 1: industry, which includes detailed listings of manufacturing enterprises-public and private, Greek and multinational—which are 
active-producing — in Greece. Companies that were listed as "very small" according to ICAP's directory [34] were excluded from the study as it was considered highly unlikely to have implemented ISs to support their operations. The questionnaire was sent in a total of 184 companies and 96 of them responded by the end of January 2019.

In order to achieve the maximum response rate, the survey instrument was structured as a short questionnaire [35] with a total of 15 questions-13 of which were closed-end questions, while the last two of them were open questions. The first two questions were addressed to all respondents. Specifically, the second one's objective was to determine whether the company uses information systems (IS) or not. Those responding negatively to that question were instructed to proceed to the tenth question the objective of which was to determine the reasons that prevent the companies from investing in IS. The rest of the respondents had to follow the natural course of the questionnaire. The penultimate question was asking the respondents to specify their job title. Finally, the last question was asking about their thoughts on IS and supply chain (SC) in Greek industry.

The survey instrument was developed based on the extensive review of the current literature, which was delineated in Section 3. The questionnaire was pre-tested on a pilot sample of five experts regarding IS to assess its clarity, comprehensiveness, and overall suitability. After completing the necessary amendments in November 2018, the questionnaire was sent electronically to 184 manufacturing enterprises, which were invited to fill it out on the web. An accompanying cover letter described briefly the research project and provided assurance that the information obtained from participating companies will be treated as confidential. Most of the e-mail addresses were found in the ICAP's directory [34]. Few other email addresses were found on the General Commercial Registry's site [36], as well as, the Exporters' Association of Northern Greece's site [37]. All the companies-whether we had found the email addresses or not-were contacted by phone to verify or be given the e-mail addresses (so as to send them the questionnaire) but also to inform them about the research. In order to increase the response rate, three weeks after the first invitation the questionnaire was emailed again to all those companies that had not responded. Furthermore, another email was sent after Christmas holidays that was followed by phone contact. In total of 184 companies that were contacted, 96 were returned by the end of January 2019.

Returned questionnaires underwent strict checks to ensure completeness and consistency. The whole number of them that was answered was found to be valid and usable for further analysis, which puts the overall response rate to $52.17 \%$.

The sample was also checked for representativeness with respect to the industry sector and also the district they facilitate. In both instances the $X^{2}$ goodness-of-fit test shows that the sectorial or the district representation of the sample does not differ significantly from that observed in the total population of manufacturing enterprises in Northern Greece. The $p$-value of the test (minimal significance level for rejection of the null hypothesis) was 0.813 for the sectorial representativeness and 0.717 for the district representativeness, respectively [38].

The questionnaire was also tested with the Cronbach Alpha method for its reliability. The Cronbach Alpha index value was found to be equal to 0.856 which is considered to be a very good value for validation [39].

\section{Results and Discussion}

\subsection{General Characteristics}

Table 1 and Figure 1 show the profile of the companies with respect to the district they facilitate and the industry sector accordingly. The total number of companies appearing in Table 1 and Figure 1 is the whole amount of the responses (96) since they were all identified. In both cases the "other" represents districts or industry sectors with no more than five responses. 
Table 1. Profile of the companies: District they facilitate.

\begin{tabular}{ccc}
\hline District & Number of Companies & Percentage \\
\hline Thessaloniki & 21 & $21.9 \%$ \\
Kilkis & 11 & $11.5 \%$ \\
Drama & 9 & $9.4 \%$ \\
Serres & 8 & $8.3 \%$ \\
Imathia & 8 & $8.3 \%$ \\
Pieria & 7 & $7.3 \%$ \\
Rodopi & 6 & $6.3 \%$ \\
Xanthi & 6 & $6.3 \%$ \\
Other & 20 & $20.9 \%$ \\
\hline
\end{tabular}

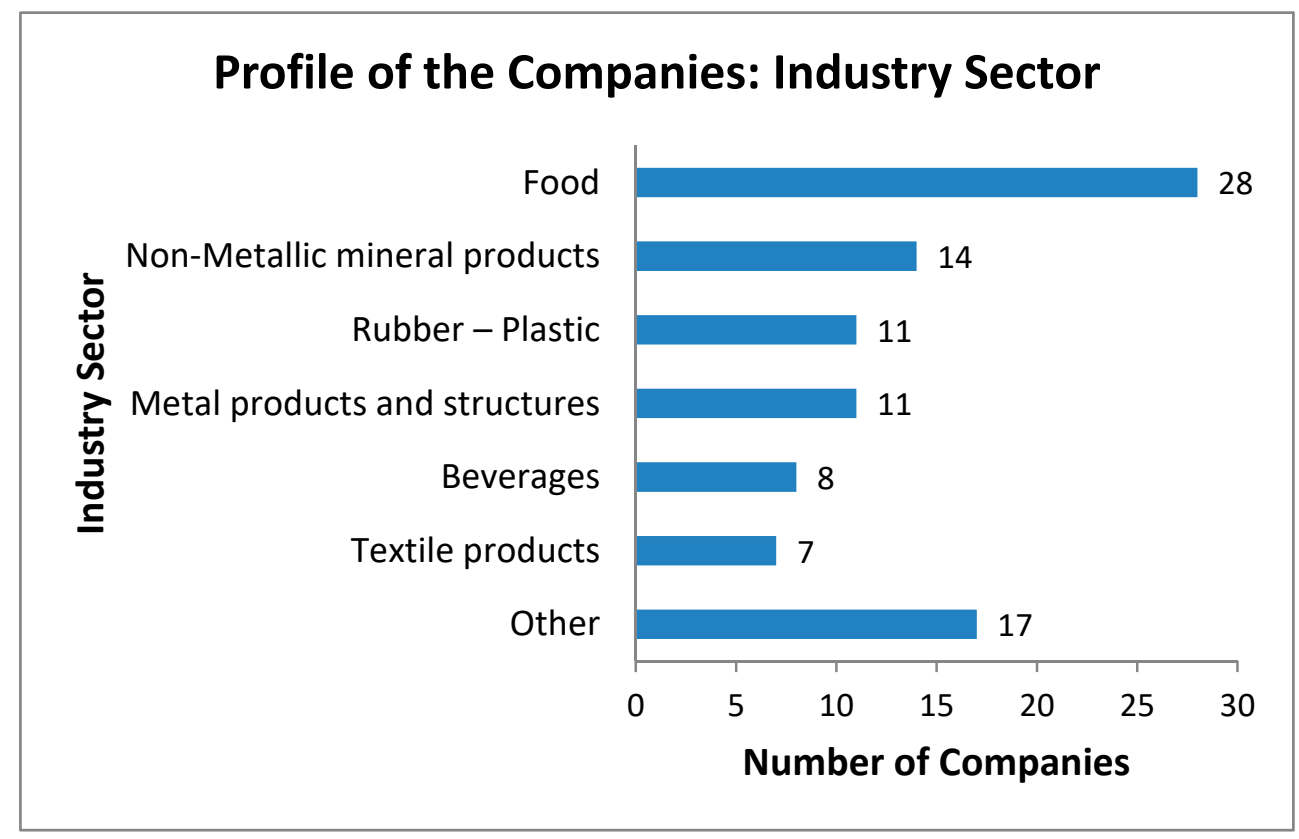

Figure 1. Profile of the companies: Industry sector.

\subsubsection{Information Systems (ISs) (RQ1)}

The majority of the respondents 83 out of 96 stated that the companies they work for, they use IS while 13 of them do not. Of the 83 companies the 82 specified which systems they actually use (Table 2). The majority of the companies use ERP (85.4\%). Quite enough of them-32, 31, and 29-use WMS, OMS, and CRM, respectively. The rest of the systems have a percentage of less than $26 \%$ each of them. It would be interesting to notice that the SCM which is an area that is in development and will continue to be in the years to come is only used by $13.4 \%$ of the companies. As we referred previously in these days the competition has moved or moves from company-company to supply chain-supply chain. The percentages sum up to much more than 100 percent because most companies use multiple ISs.

Comparing the current research with the one that was conducted by Ketikidis et al. [10] one can observe differences or similar results regarding the percentage of the companies regarding the adoption of an IS. Even if the percentages of current and future users of the ERP system are added [10] the percentage (49\%) is much lower of that in the current research $(85.4 \%)$. On the other hand the percentage of the companies in the current research which use systems such as WMS, MRP, SCM, SRM, and APS are lesser than the companies they were already using those systems in the [10] research. The percentage of the companies which use CRM in the current research is between the percentages of those they were already using the system but not greater if we add those were intended to implement it in the future. 
Table 2. Information systems in use.

\begin{tabular}{ccc}
\hline Information System & Number of Companies & Percentage \\
\hline ERP & 70 & $85.4 \%$ \\
WMS & 32 & $39.0 \%$ \\
OMS & 31 & $37.8 \%$ \\
CRM & 29 & $35.4 \%$ \\
MES & 21 & $25.6 \%$ \\
MRP & 17 & $20.7 \%$ \\
SCM & 11 & $13.4 \%$ \\
SRM & 11 & $13.4 \%$ \\
TMS & 8 & $9.8 \%$ \\
DRP & 6 & $7.3 \%$ \\
APS & 6 & $7.3 \%$ \\
Other & 3 & $3.7 \%$ \\
\hline
\end{tabular}

More than half companies, 47 out of 83 , have stated that they invested in IS the last couple of years which means that they care about their systems being up to date (Figure 2). On the other hand, only eight of them have not invested in IS in the last 10 years besides the financial crisis that hit the country.

\section{Last time the company invested in Information Systems}

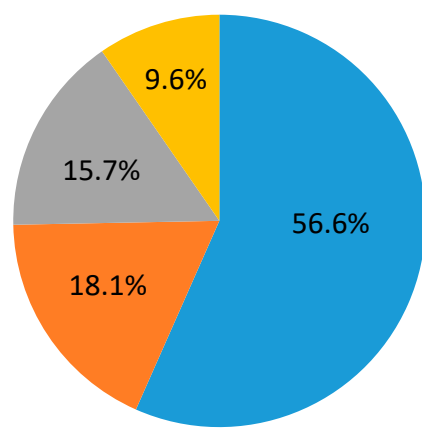

0-2 years ago

3-5 years ago

6-10 years ago

Over 10 years ago

Figure 2. Last time the companies invested in IS.

\subsubsection{Profitability of IS Adoption (RQ2)}

Of the 83 companies that use IS the 82 of them answered this question. The estimate of this research, based on the respondents sample is that $92.7 \%$ of the companies find IS adoption profitable at a high or at least a satisfactory level (Figure 3). On the other hand, there is just one company that considers IS adoption as non-profitable at all. Another $6.1 \%$ of the companies have only recently installed the IS so they cannot provide yet a clear image regarding the results of the implementation.

There are several aspects that affect the financial gains due to ERP implementation which leads to controversial results depending on the company [40]. Larger companies showed better results in financial measures than smaller companies. According to Ata and Toker [41] CRM adoption does not affect the organization's financial performance. Additionally, some companies although they spent enormous amounts of money to implement an IS they had no positive results regarding their business performance [42]. One the other hand other studies [43] concluded that ERP adoption influenced positively the firm's profitability. Similarly, Ye and Wang [44] were led to the conclusion that IT adoption leads to better performances regarding profit margins. 


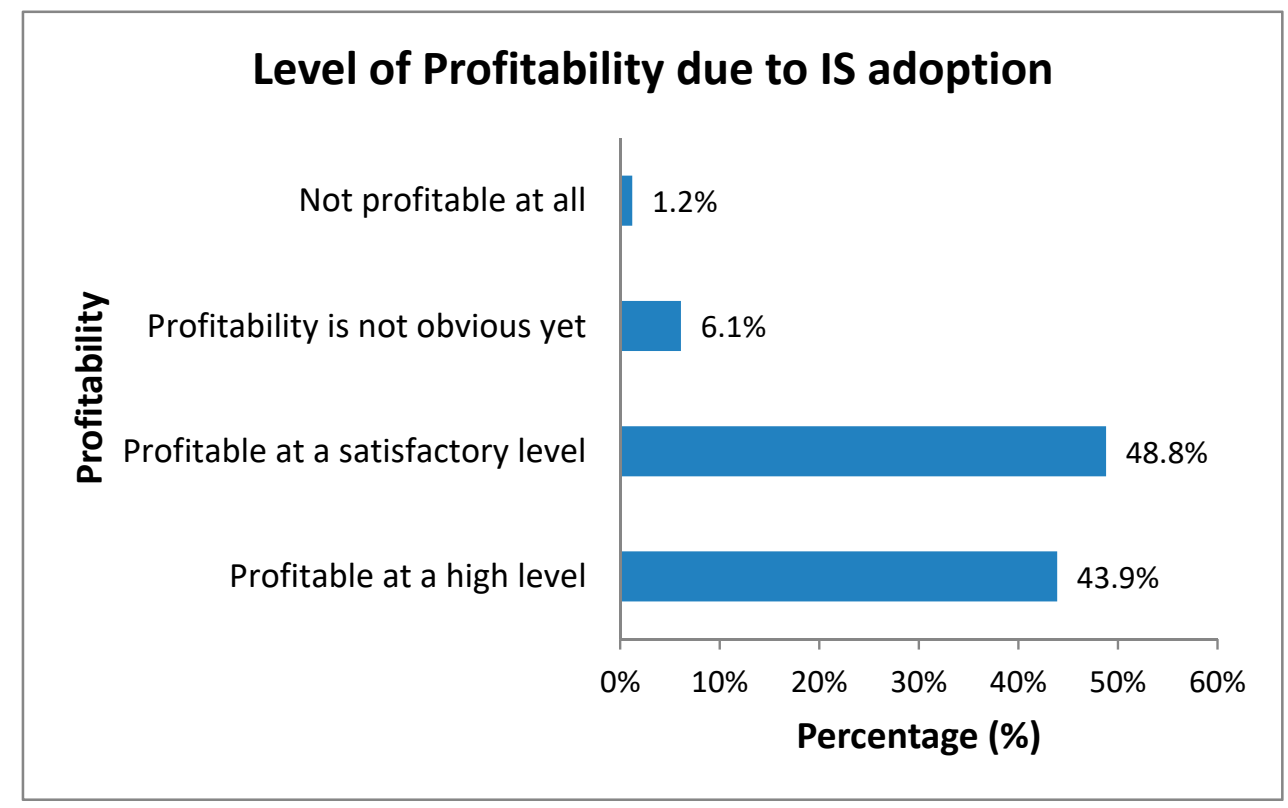

Figure 3. Level of profitability due to IS adoption.

\subsubsection{Motivation for IS Adoption (RQ3)}

All the companies that use IS were asked to indicate how important they consider each of the seven driving factors that have been discussed in Section 3.3, by rating them on a five-point Likert scale with 1-“the least important" —and 5-“extremely important". The average ratings are shown in Figure 4. All driving factors have an average score above 3.5 which means all of them are considered important. In addition to the two of them-competitive advantage and select appropriate suppliers-the rest are considered as at least "very important" motivators for a company to adopt an IS.

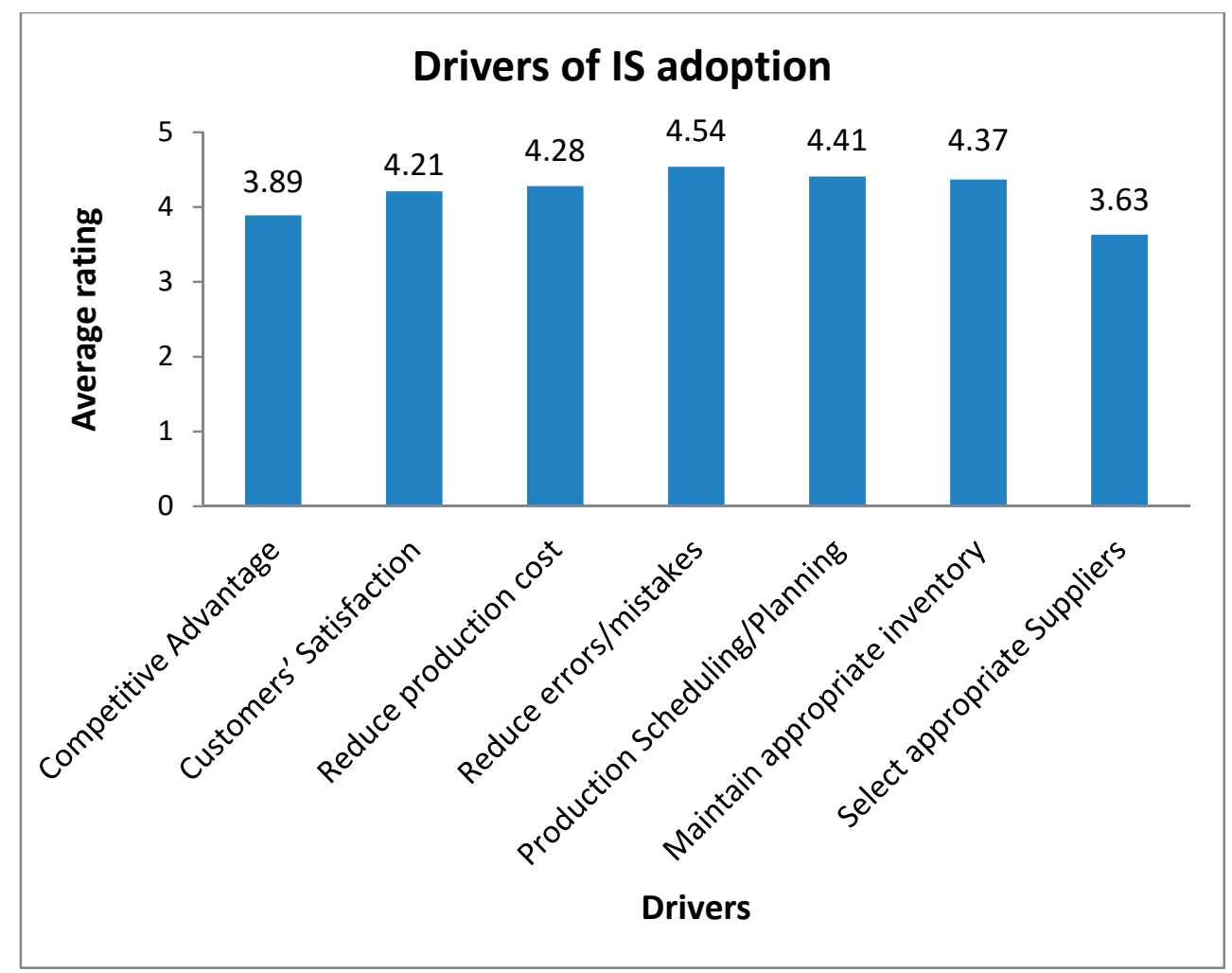

Figure 4. Drivers of IS adoption. 
The current research is in accordance to several researches $[28,29,45,46]$ that have been conducting regarding information systems (ISs) and they consider competitive advantage as an important motivator that forces companies to seek to adopt these technologies or update with newer versions or add-ons those they already use. Although in the current study most of the other motivators are considered more important than "competitive advantage". In addition to competitive advantage being a key motivator Apulu and Latham [29] recognize other two important drivers of IS adoption which are customer satisfaction and reduce cost. Providing better customer services and in a way aimed for customer satisfaction is an important element that has been taken into account during the assessment, selection and adoption stages of an IS [47]. The most profound choice on that effect and the one that is specifically designed to serve the customers seem to be CRM [23] even in B2B (Business to business) markets [41] in which customer satisfaction is also considered as a performance measure. Of course, that does not rule out other forms of IS that can be used for that effect such as: customer satisfaction or generally providing better service to the customers $[27,47,48]$. Ketikidis et al. [10] use several forms of information technology in an attempt to minimize cost. Similarly, cost reduction is considered a major objective in other researches too [14,48]. Cost savings was also a great concern for respondents in Koh et al. research [31]. According to Fuchs et al. [12] the production process is too complex to be conducted without an IS that will help not only large companies but also the SMEs. Generally, production planning and control can be considered as the second-best motivation for implementing an IS [31]. In the current research Production planning is the second more important driver for IS adoption. Companies aim for low inventory levels in order to attain better inventory management [9] which reduces overproduction. The least important factor that motivates companies to adopt an IS is to select appropriate suppliers. If the company and its supplier have systems that can be integrated that could be positive for their supply chain but that does not mean that it is a priority for them-the integrated systems or suppliers with the latest systems available [12,31]. Mostly the benefits that are obtained due to IS/IT adoption in the supplier selection process are non-financial and more relative to management decisions [22].

\subsubsection{Barriers of IS Adoption (RQ4)}

In the tenth question of the questionnaire the respondents were asked to assess the importance of specific obstacles to the IS adoption, by rating them on the five-point Likert scale (1: "the least important" and 5: "extremely important"). That question was answered by all the respondents whether they have adopted an IS or not. The six inhibitors that were explicitly mentioned in the questionnaire are those that are described in Section 3.4. Figure 5 contains the average ratings of the six barriers. All barriers-but one-have a score that puts them between being of "medium importance" and "very important". Most important barrier is considered to be the "cost of IS" that the companies seek to adopt. Employee's opposition does not seem to be much of an important barrier with an average score of 1.77 .

The cost of an IS system seems to be one of the most important-if not the most important-barrier in other studies, too, not only because of the cost to buy it, but also due to the additional costs-implementation costs, employee training, upgrading existing facilities, maintenance etc.- - it might bring along. Those must be taken into consideration especially in SMEs [6,32,49-51]. Economic crisis might have a negative impact on a company's efforts to apply innovations which might lead to problems in its financial performance [41]. Giotopoulos et al. [6] suggest that despite the financial crisis that Greece has been hit IT might play a crucial role in the country's attempts to recover and develop. In the current research companies seem to be reluctant enough to adopt a new system when the one they already have is sufficient enough or it satisfies them completely. Several researchers acknowledge that sometimes employees are reluctant to change and they oppose adopting new technologies, especially if they believe the new process is not going to be better than the one they already use $[5,31,33]$. It is important for the companies to 
communicate - especially with the lower-level employees—-the changes they need to be done and try to motivate them to go along and not resist.

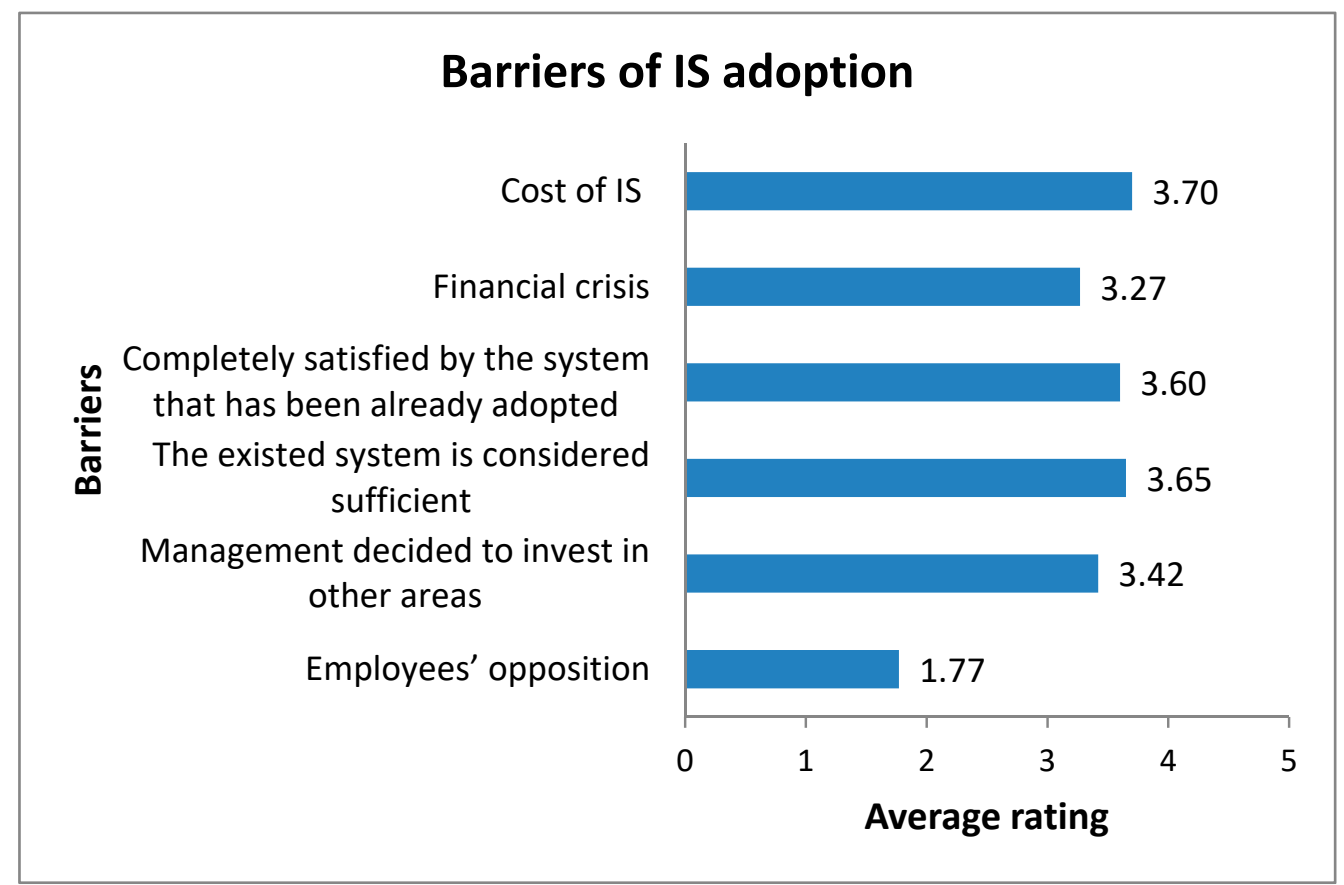

Figure 5. Barriers of IS adoption.

In literature there is also another barrier that is considered important and seems to be verified by the current research. That is the size of the company in regards to its employees $[14,15]$. The larger the company the greater the possibility of using-more advanced-IS (e.g., ERP). Small-medium companies that are able to do the job in other ways are not probable to adopt IS or they continue to use an older kind of IS (e.g., MRP) [10]. In the current research all the companies that are not using IS, are those with no more than 50 employees. On the other hand Fuchs et al. [12] suggest that the size of the company might not be an issue regarding the company's decision to adopt IT since the companies could use IT systems that are most suitable to them, such as less complex ERP suites and not ERP that is mostly used and can be afforded by larger companies.

\subsection{Comparisons Regarding the Factors Which Affect Drivers and Barriers of IS Adoption}

In the following Sections 5.2.1 and 5.2.2, the Mann-Whitney two-sample U-test is used to assess differences between two identified different groups that will be described accordingly, regarding the barriers (Section 5.2.1) and the motivators and barriers (Section 5.2.2) that were measured on the five-point Likert scale. That non-parametric test is regarded as particularly powerful for analyzing data collected in a mail survey [38]. The U-tests indicate significant differences between the respective two groups in each case only if the $p$-value is lower than 0.05 . Otherwise, the U-tests indicate that the respective null hypotheses of no difference cannot be rejected at a significance level lower than $0.05 \%$.

\subsubsection{IS Adoption (RQ5)}

Based on the analysis of the exploratory question in the first part of the questionnaire, two groups of companies were identified in the whole sample: those that have adopted IS (IS1) and those which haven't adopted IS (IS0). This paper investigates whether there are statistically significant differences between the two groups regarding the reasons that would prevent them from adopting an IS (Table 3). 
Table 3. Barriers of IS adoption-use of information systems.

\begin{tabular}{cccc}
\hline \multirow{2}{*}{ Barriers } & \multicolumn{2}{c}{ Average Rating } & \multirow{2}{*}{-Values } \\
\cline { 2 - 3 } & Using IS & Not Using IS & \\
\hline Cost of IS & 3.81 & 2.82 & 0.004 \\
Financial crisis & 3.36 & 2.64 & 0.080 \\
Completely satisfied by the system that has been & 3.56 & 3.83 & 0.408 \\
already adopted & 3.63 & 3.75 & 0.700 \\
The existed system is considered sufficient & 3.51 & 2.73 & 0.144 \\
Management decided to invest in other areas & 1.85 & 1.18 & 0.023 \\
Employees' opposition & & &
\end{tabular}

The results show that IS0 differs significantly from IS1 companies only with respect to the two following barriers: Cost of IS ( $p$-value $=0.004)$ and employee's opposition $(p$-value $=0.023)$. In regards with the rest of the barriers it seems through the $p$-values that there are no statistically significant differences between the two independent groups of companies. That implies that the respondents of IS0 and IS1 evaluate the rest of the barriers the same way.

\subsubsection{Profitability of IS Adoption (RQ6)}

Based on the analysis of the exploratory question in the first part of the questionnaire, two prominent different groups of companies were initially identified in the sample that has stated that they use IS, as shown in Figure 6: Those which consider that the IS adoption leads to high level of profitability (IS1_H $=\mathrm{n}_{1}=36$ ) and those that obtained relatively satisfying level of profitability due to IS adoption (IS1_RS $=n_{2}=40$ ). Through this research there is an effort to assess whether there are statistically significant differences between the two groups regarding the reasons that motivate them to adopt IS (Table 4) and also the barriers that would prevent them to adopt IS (Table 5).

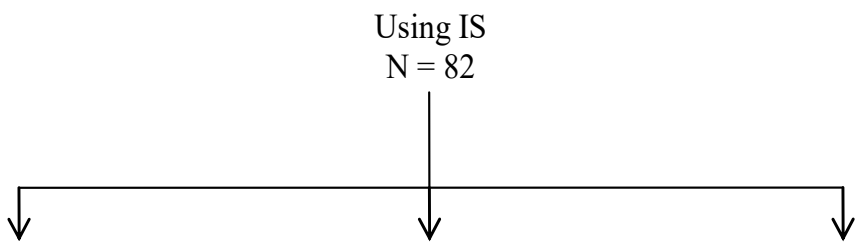

High profitability Relatively satisfying profitability Not clear yet/Not profitable

$\begin{array}{lcc}\text { IS1_H } & \text { IS1_RS } & \mathrm{n}_{3}=6 \\ \mathrm{n}_{1}=36 & \mathrm{n}_{2}=40 & \end{array}$

Figure 6. Profile of the respondents they have adopted IS with respect to the level of profitability.

Table 4. Drivers for IS adoption-level of profitability.

\begin{tabular}{cccc}
\hline \multirow{2}{*}{ Drivers } & \multicolumn{2}{c}{ Average Rating } & \\
\cline { 2 - 3 } & $\begin{array}{c}\text { High Level of } \\
\text { Profitability }\end{array}$ & $\begin{array}{c}\text { Profitable in Relatively } \\
\text { Satisfying Level }\end{array}$ & $p$-Value \\
\hline Competitive Advantage & 4.28 & 3.70 & 0.003 \\
Customers' Satisfaction & 4.31 & 4.18 & 0.596 \\
Reduce production cost & 4.44 & 4.23 & 0.264 \\
Reduce errors/mistakes & 4.75 & 4.42 & 0.024 \\
Production Scheduling/Planning & 4.58 & 4.33 & 0.042 \\
Maintain appropriate inventory & 4.53 & 4.30 & 0.173 \\
Select appropriate Suppliers & 4.06 & 3.36 & 0.005
\end{tabular}


Table 5. Barriers of IS adoption—level of profitability.

\begin{tabular}{cccc}
\hline & \multicolumn{2}{c}{ Average Rating } & \\
\cline { 2 - 3 } Barriers & $\begin{array}{c}\text { High Level of } \\
\text { Profitability }\end{array}$ & $\begin{array}{c}\text { Profitable in Relatively } \\
\text { Satisfying Level }\end{array}$ & $p$-Value \\
\hline $\begin{array}{c}\text { Cost of IS } \\
\text { Financial crisis }\end{array}$ & 3.75 & 3.90 & 0.530 \\
$\begin{array}{c}\text { Completely satisfied by the system } \\
\text { that has been already adopted }\end{array}$ & 3.28 & 3.46 & 0.472 \\
$\begin{array}{c}\text { The existed system is considered } \\
\text { sufficient }\end{array}$ & 3.61 & 3.55 & 0.618 \\
$\begin{array}{c}\text { Management decided to invest in } \\
\text { other areas }\end{array}$ & 3.72 & 3.58 & 0.376 \\
Employees' opposition & 3.31 & 3.66 & 0.307 \\
\hline
\end{tabular}

In regards with the driving factors of IS adoption the results show that IS1_H differ significantly from IS1_RS companies only with respect of the four following motivators: Competitive advantage $(p$-value $=0.003)$, reduce errors $(p$-value $=0.024)$, production planning $(p$-value $=0.042)$, and select appropriate suppliers $(p$-value $=0.005)$. There is no difference between the two groups in regards to the rest motivating factors regarding the drivers of IS adoption. That is also the conclusion about these two groups regarding the barriers of IS adoption since $p$-value is greater than 0.05 in each one of them, which means that the respondents of these two groups are thinking alike.

\section{Summary, Discussion, and Conclusions}

This empirical research addresses issues regarding the use of IS in Northern Greek industry, the drivers and barriers of their implementation, as well as the cost efficiency due to IS adoption. The statistical analysis of the responses in the 96 questionnaires filled by Northern Greek manufacturing companies leads us to some very interesting results.

Northern Greek manufacturers have adopted IS in a percentage of $86.5 \%$ (83 out of 96). The vast majority of them have implemented the ERP system (85.4\%). WMS, OMS, and CRM are the next in line with a respective percentage of $39.0 \%, 37.8 \%$, and $35.4 \%$. It is also worthwhile to refer that SCM is used only by $13.4 \%$ of the companies. In addition to the financial crisis that the country has suffered since 2009 the majority of the companies which use IS (90.4\%) they have invested in an IS in the last decade.

Of those which have adopted an IS the vast majority consider that has led to a high or relatively satisfying level of profitability for the company. A company's desire to reduce the errors is considered to be the main motivation to adopt an IS, while production planning is the second best. The greatest inhibitor for any company-whether they use IS or not-is the cost of the system they consider to adopt. On the other hand, any negative reaction from the employees is not considered such a significant barrier. Companies that have adopted IS mostly consider its cost as a great barrier to invest in IS compared to those which have not adopted one. To those that do not use an IS, having a current system that satisfies them completely is a major inhibitor not to invest in an IS.

Both companies with high or relatively satisfying level of profitability seek firstly to reduce the errors as a motivator to invest in IS, yet there is a statistically significant difference between these two groups. In addition, those with high level of profitability have given higher average ratings in every variable on Table 4 regarding those with relatively satisfying level of profitability. In fact, the first ones consider every motivating factor at least "very important" (4) in a five-point Likert scale. The major inhibitor for investing in IS for both groups, is its cost.

A closer observation of Figure 4-the motivating factors to adopt an IS-could lead to a very interesting logic that seems to be followed by the respondents which could be described as: "from internal to external". In other words, for every company its priority regarding choosing an IS is to solve its internal problems (error reduction, better production 
planning, maintain appropriate inventory, reduce production cost), and then it expands its viewpoints to the external environment (customer satisfaction, competitive advantage, select appropriate suppliers).

In regards of the barriers that would prevent a company from investing in IS, it is important to note that the "employee's opposition" is not considered as a significant inhibitor. Although it would be good for the company to inform the employees and try to find ways to limit their counteractions as much as possible, so as to make them go along. The cost of an IS is the number one inhibitor. In addition to its actual cost, companies have to consider its implementation cost, its integration cost with the already existing systems, probable employees educational costs, etc. Along with these they also have to think of the time that would be needed for recuperation. Thus, a high cost would prevent them from investing in an IS, especially if the company is a small one.

Regarding the interpretation of RQ5 we can say the following: There is a significantly different way of thinking regarding the cost of IS and the employees' opposition. For those that already use an IS (IS1), the cost of IS is close to "very important" inhibitor while for those they don't use IS (IS0), it is of "medium importance". In a five-point Likert scale they have a difference of one degree in the average ratings. We can assume that IS1 companies will consider their next investment and its cost more carefully. On the other hand, IS0 companies will probably consider the cost of IS as a "necessary evil" for their company's modernization. Similarly, IS1 enterprises will consider a little more the employees' opposition, while on the other hand for the IS0 enterprises it does not seem to be of any importance. Again, we can pinpoint for the companies that have not adopted IS yet, the modernization for that decision and also the effort for gaining other benefits such as competitive advantage, error reduction, etc.

Trying to interpret RQ6 one can realize that the two groups of companies-those that have high level of profitability (IS_H) and those that have a relatively satisfying profitability (IS_RS)—-have a similar way of thinking regarding the barriers that would prevent them from investing in a new IS - since they already have at least one. They both consider its cost as the most important barrier and employees' opposition as the least one. However, a comparison between these two groups regarding the motivating factors that would force them to invest in an IS can show that there are differences in regards to the competitive advantage, the error reduction, the production planning and the selection of the appropriate suppliers. In all these four occasions IS_H companies consider those factors more important regarding the IS_RS companies. It can be said that just because they aim at better results on those four factors with the IS they implement that is why they are more profitable. In other words, those motivating factors make a difference.

Additionally, the barriers which were involved in the current research, there is a rather silent one that has to do with the company's size. All of the companies that have not adopted an IS they employ no more than 50 employees. That being said, it is understandable that it is more difficult for a small company to invest in IS.

Generally speaking, it can be said that this research has shown that Northern Greek manufacturing companies use IS and they have realized that it helps them financially. Although the numbers show that they can do better and that there are still companies that could choose that path.

At this point, it is important to explicitly acknowledge a limitation of this research regarding the area that was conducted since the research was focused only on the manufacturing companies of Northern Greece and not those of the entire country.

Although the representation of the sample does not differ from that of the population in regards to the sector and the district the company operates, nonetheless it would be interesting to be able to have answers from the whole country. Additionally, it would be interesting to research about specific ISs - such as ERP, etc.-about what they offer in specific areas of a company's supply chain as well as to its operations. Another future research could focus on the implementation of SCM along with the motives and barriers of its adoption, in the whole country. 
Author Contributions: Investigation, A.K.; Methodology, P.K.; Project administration, P.K.; Resources, A.K.; Software, A.K.; Supervision, P.K.; Writing-original draft, A.K.; Writing一review \& editing, P.K. All authors have read and agreed to the published version of the manuscript.

Funding: This research received no external funding.

Institutional Review Board Statement: Not applicable.

Informed Consent Statement: Not applicable.

Acknowledgments: The authors gratefully acknowledge the contribution of George Tagaras for his valuable comments. The authors would also like to thank all the companies that participated in the survey.

Conflicts of Interest: The authors declare no conflict of interest.

\section{References}

1. Longinidis, P.; Gotzamani, K. ERP user satisfaction issues: Insights from a Greek industrial giant. Ind. Manag. Data Syst. 2009, 109, 628-645. [CrossRef]

2. Sellitto, M.A.; de Vargas, E.J. A method to align functionalities of a manufacturing execution system with competitive priorities. J. Manuf. Technol. Manag. 2019. [CrossRef]

3. Oláh, J.; Karmazin, G.; Pető, K.; Popp, J. Information technology developments of logistics service providers in Hungary. Int. J. Logist. Res. Appl. 2017, 21, 332-344. [CrossRef]

4. Türkes, M.C.; Oncioiu, I.; Aslam, H.D.; Marin-Pantelescu, A.; Topor, D.I.; Capusneanu, S. Drivers and Barriers in Using Industry 4.0: A Perspective of SMEs in Romania. Processes 2019, 7, 153. [CrossRef]

5. Rouhani, S.; Mehri, M. Empowering benefits of ERP systems implementation: Empirical study of industrial firms. J. Syst. Inf. Technol. 2018, 20, 54-72. [CrossRef]

6. Giotopoulos, I.; Kontolaimou, A.; Korra, E.; Tsakanikas, A. What drives ICT adoption by SMEs? Evidence from a large-scale survey in Greece. J. Bus. Res. 2017, 81, 60-69. [CrossRef]

7. Baruffaldi, G.; Accorsi, R.; Manzini, R. Warehouse management system customization and information availability in 3pl companies; A decision-support tool. Ind. Manag. Data Syst. 2018, 119, 251-273. [CrossRef]

8. Ho, W.; Xu, X.; Dey, P.K. Muticriteria decision making approaches for supplier evaluation and selection: A literature review. Eur. J. Oper. Res. 2010, 202, 16-24. [CrossRef]

9. Li, G.; Yang, Y.; Sun, L.; Sohal, A.S. The impact of IT implementation on supply chain integration and performance. Int. J. Prod. Econ. 2009, 120, 125-138. [CrossRef]

10. Ketikidis, P.H.; Koh, S.C.L.; Dimitriadis, N.; Gunasekaran, A.; Kehajova, M. The use of information systems for logistics and supply chain management in South East Europe: Current status and future direction. Omega 2008, 36, 592-599. [CrossRef]

11. Tripathy, S.; Aich, S.; Chakraborty, A.; Lee, G.M. Information technology is an enabling factor affecting supply chain performance in Indian SMEs: A structural equation modeling approach. J. Model. Manag. 2016, 11, 269-287. [CrossRef]

12. Fuchs, C.; Beck, D.; Lienland, B.; Kellner, F. The role of IT in automotive supplier supply chains. J. Enterp. Inf. Manag. 2018, 31, 64-88. [CrossRef]

13. Fuchs, C.; Otto, A. Value of IT in supply chain planning. J. Enterp. Inf. Manag. 2015, 28, 77-92. [CrossRef]

14. Barbosa, D.H.; Musetti, M.A. Logistics information systems adoption: An empirical investigation in Brazil. Ind. Manag. Data Syst. 2010, 110, 787-804. [CrossRef]

15. Kannabiran, G.; Dharmalingam, P. Enablers and inhibitors of advanced information technologies adoption by SMEs: An empirical study of auto ancillaries in India. J. Enterp. Inf. Manag. 2012, 25, 186-209. [CrossRef]

16. Shatat, A.S.; Udin, Z.M. The relationship between ERP system and supply chain management performance in Malaysian manufacturing Companies. J. Enterp. Inf. Manag. 2012, 25, 576-604. [CrossRef]

17. Haseeb, M.; Hussain, H.I.; Slusarczyk, B.; Jermsittiparsert, K. Industry 4.0: A Solution towards Technology Challenges of Sustainable Business Performance. Soc. Sci. 2019, 8, 154. [CrossRef]

18. Wereda, W.; Wozniak, J. Building Relationships with Customer 4.0 in the Era of Marketing 4.0: The Case Study of Innovative Enterprises in Poland. Soc. Sci. 2019, 8, 177. [CrossRef]

19. Lee, E.K.; Ha, S.; Kim, S.K. Supplier selection and management system considering relationships in supply chain management. IEEE Trans. Eng. Manag. 2001, 48, 307-319.

20. Arvanitis, S.; Loukis, E.; Diamantopoulou, V. The effect of soft ICT capital on innovation performance of Greek firms. J. Enterp. Inf. Manag. 2013, 26, 679-701. [CrossRef]

21. Brynjolfsson, E.; Saunders, A. Wired for Innovation-How Information Technology Is Reshaping the Economy; The MIT Press: Cambridge, MA, USA, 2010.

22. Ageron, B.; Gunasekaran, A.; Spalanzani, A. IS/IT as supplier selection criterion for upstream value chain. Ind. Manag. Data Syst. 2013, 113, 443-460. [CrossRef] 
23. Valmohammadi, C. Customer relationship management: Innovation and performance. Int. J. Innov. Sci. $2017,9,374-395$. [CrossRef]

24. Brynjolfsson, E.; Hitt, L.M. Paradox lost? Firm-level evidence on the returns to information systems. Manag. Sci. 1996, 42, 541-558. [CrossRef]

25. Devaraj, S.; Kohli, R. Information technology payoff in the healthcare industry: A longitudinal study. J. Manag. Inf. Syst. 2000, 16, 41-67. [CrossRef]

26. Hartman, A. Why tech falls short of expectations. Optimize 2002, 4, 20-27.

27. Galy, E.; Sauceda, M.J. Post-implementation practices of ERP systems and their relationship to financial performance. Inf. Manag. 2014, 51, 310-319. [CrossRef]

28. Nguyen, T.H.; Sherif, J.S.; Newby, M. Strategies for successful CRM Implementation. Inf. Manag. Comput. Secur. 2007, 15, 102-115. [CrossRef]

29. Apulu, I.; Latham, A. Drivers for information and communication technology adoption: A case study of Nigerian small and medium sized enterprises. Int. J. Bus. Manag. 2011, 6, 51. [CrossRef]

30. Vasista, T.G.; Abone, A. Benefits: Barriers and Applications of Information Communication Technology in Construction Industry: A Contemporary Study. Int. J. Eng. Technol. 2018, 7, 492-499. [CrossRef]

31. Koh, S.C.L.; Simpson, M.; Padmore, J.; Dimitriadis, N.; Misopoulos, F. An exploratory study of enterprise resource planning adoption in Greek companies. Ind. Manag. Data Syst. 2006, 106, 1033-1059. [CrossRef]

32. Somuyiwa, A.; Adebayo, T. Analysis of information and communication technologies (ICT) usage on logistics activities of manufacturing companies in Southwestern Nigeria. J. Emerg. Trends Econ. Manag. Sci. 2011, 2, 68-74.

33. Dezdar, S.; Ainin, S. The influence of organizational factors on successful ERP implementation. Manag. Decis. 2011, 49, 911-926. [CrossRef]

34. ICAP's Greek Financial Directory. Available online: https://www.icap.gr/en/ (accessed on 19 April 2019).

35. Cooper, D.R.; Schindler, P.S. Business Research Method, 11th ed.; McGraw-Hill: New York, NY, USA, 2011.

36. General Commercial Registry. Available online: http:/ / www.businessportal.gr/home/index_en (accessed on 25 February 2019).

37. Exporters' Association of Northern Greece. Available online: https:/ /www.seve.gr/en/ (accessed on 14 March 2019).

38. Sheskin, D. Handbook of Parametric and Nonparametric Statistical Procedures, 4th ed.; Chapman \& Hall: New York, NY, USA, 2007.

39. Garson, D. Validity \& Reliability; Statistical Associates Publishing: Asheboro, NC, USA, 2016.

40. Beheshti, H.M.; Beheshti, C.M. Improving productivity and firm performance with enterprise resource planning. Enterp. Inf. Syst. 2010, 4, 445-472. [CrossRef]

41. Ata, U.Z.; Toker, A. The effect of customer relationship management adoption in business-to-business markets. J. Bus. Ind. Mark. 2012, 27, 497-507.

42. Gupta, M.; Kohli, A. Enterprise resource planning systems and its implications for operations function. Technovation 2006, 26, 687-696. [CrossRef]

43. Hendricks, K.B.; Singhal, V.R.; Stratman, J.K. The impact of enterprise systems on corporate performance: A study of ERP, SCM, and CRM system implementations. J. Oper. Manag. 2007, 25, 65-82. [CrossRef]

44. Ye, F.; Wang, Z. Effects of information technology alignment and information sharing on supply chain operational performance. Comput. Ind. Eng. 2013, 65, 370-377. [CrossRef]

45. Lin, R.J.; Chen, R.H.; Chiu, K.K.S. Customer relationship management and innovation capability: An empirical study. Ind. Manag. Data Syst. 2010, 110, 111-133. [CrossRef]

46. Valmohammadi, C. Investigating innovation management practices in Iranian organizations. Innov. Manag. Policy Pract. 2012, 12, 247-255. [CrossRef]

47. Su, Y.F.; Yang, C. Why are enterprise resource planning systems indispensable to supply chain management? Eur. J. Oper. Res. 2010, 203, 81-94. [CrossRef]

48. Perego, A.; Perotti, S.; Mangiaracina, R. ICT for logistics and freight transportation: A literature review and research agenda. Int. J. Phys. Distrib. Logist. Manag. 2011, 41, 457-483. [CrossRef]

49. Ghobakhloo, M.; Sabouri, M.S.; Hong, T.S.; Zulkifli, N. Information technology adoption in small and medium-sized enterprises; an appraisal of two decades literature. Interdiscip. J. Res. Bus. 2011, 1, 53-80.

50. Tan, K.S.; Chong, S.C.; Lin, B.; Eze, U.C. Internet-based ICT adoption among SMEs. J. Enterp. Inf. Manag. 2010, $23,27-55$. [CrossRef]

51. Dixit, A.K.; Prakash, O. A study of issues affecting ERP implementation in SMEs. Int. Ref. Res. J. 2011, 2, 77. 